\title{
Earthquake-related versus non-earthquake-related injuries in spinal injury patients: differentiation with multidetector computed tomography
}

\author{
Zhi-hui Dong ${ }^{1}$, Zhi-gang Yang ${ }^{1,2^{*}}$, Tian-wu Chen ${ }^{1}$, Zhi-gang Chu', Qi-ling Wang ${ }^{1}$, Wen Deng ${ }^{1}$, Joseph C Denor ${ }^{3}$
}

\begin{abstract}
Introduction: In recent years, several massive earthquakes have occurred across the globe. Multidetector computed tomography (MDCT) is reliable in detecting spinal injuries. The purpose of this study was to compare the features of spinal injuries resulting from the Sichuan earthquake with those of non-earthquake-related spinal trauma using MDCT.

Methods: Features of spinal injuries of 223 Sichuan earthquake-exposed patients and 223 non-earthquake-related spinal injury patients were retrospectively compared using MDCT. The date of non-earthquake-related spinal injury patients was collected from 1 May 2009 to 22 July 2009 to avoid the confounding effects of seasonal activity and clothing. We focused on anatomic sites, injury types and neurologic deficits related to spinal injuries. Major injuries were classified according to the grid 3-3-3 scheme of the Magerl (AO) classification system.

Results: A total of 185 patients (82.96\%) in the earthquake-exposed cohort experienced crush injuries. In the earthquake and control groups, 65 and 92 patients, respectively, had neurologic deficits. The anatomic distribution of these two cohorts was significantly different $(P<0.001)$. Cervical spinal injuries were more common in the control group (risk ratio $(R R)=2.12, P<0.001$ ), whereas lumbar spinal injuries were more common in the earthquake-related spinal injuries group (277 of 501 injured vertebrae; 55.29\%). The major types of injuries were significantly different between these cohorts $(P=0.002)$. Magerl AO type A lesions composed most of the lesions seen in both of these cohorts. Type $B$ lesions were more frequently seen in earthquake-related spinal injuries $(R R=$ 1.27), while we observed type $C$ lesions more frequently in subjects with non-earthquake-related spinal injuries $(\mathrm{RR}=1.98, P=0.0029)$.

Conclusions: Spinal injuries sustained in the Sichuan earthquake were located mainly in the lumbar spine, with a peak prevalence of type A lesions and a high occurrence of neurologic deficits. The anatomic distribution and type of spinal injuries that varied between earthquake-related and non-earthquake-related spinal injury groups were perhaps due to the different mechanism of injury.
\end{abstract}

\section{Introduction}

The magnitude 8.0 Sichuan earthquake that happened at 2:28 PM Beijing time on 12 May 2008 injured an estimated 374,643 people. A retrospective study of the features of 223 patients with spinal injuries was performed using multidetector computed tomography (MDCT). This study relied on the 2,728 patients with earthquakerelated spinal injuries seen in a key university hospital [1].

\footnotetext{
* Correspondence: yangzg1117@yahoo.com.cn

'Department of Radiology, West China Hospital of Sichuan University,

Chengdu 610041, China

Full list of author information is available at the end of the article
}

Located $92 \mathrm{~km}$ from the Wenchuan County epicenter, this 4,300-bed hospital served as an important intact rescue center immediately following the earthquake.

Spinal injuries account for 13.0-15.2\% of earthquakerelated trauma patients [2,3] and 1.6-10\% of all other trauma patients $[4,5]$. In general, the major etiologies of spinal injuries include motor vehicle accidents, falls, athletic mishaps, penetrating injuries and industrial accidents [6,7]. In contrast, the spinal injuries sustained by the 223 patients during the Sichuan earthquake usually occurred from crush injuries followed by falls. Although the features of earthquake-related spinal injuries have
C Biomed Central

() 2010 Dong et al.; licensee BioMed Central Ltd. This is an open access article distributed under the terms of the Creative Commons Attribution License (http://creativecommons.org/licenses/by/2.0), which permits unrestricted use, distribution, and reproduction in any medium, provided the original work is properly cited. 
been studied [1], no one has reported the differences between earthquake-related and other spinal injuries. We propose that there is a difference between these two types of injuries on the basis of their MDCT features because of their different injury mechanisms. MDCT is a fast and reliable modality to determine the pattern and severity of spinal injuries and the degree of spinal instability [8].

Classification based on the information provided by MDCT should provide concise information regarding the severity of the injury and guide the choice of treatment. We used MDCT alone to evaluate the difference between spinal injuries from earthquake victims and those from other causes, which may help in clinical management algorithms. We cite better disaster preparedness as an overarching goal of this investigation.

\section{Materials and methods Patients}

The study was approved by the ethics committee of our medical school, and because of the retrospective nature of this study, informed consent was waived. Of the 2,728 patients with earthquake-related spinal injuries seen in our hospital, we consecutively enrolled patients into the exposed cohort according to the following criteria: (1) the etiology of the injuries was associated with the 2008 Sichuan earthquake, (2) spinal injuries were evaluated using MDCT, and (3) the patients had not received related surgical treatment before the spinal MDCT scan. To avoid bias, we excluded patients injured in an earthquake-related motor vehicle accident. With the exception that the etiology of spinal injury was not associated with the earthquake, similar inclusive criteria were used to enroll patients into the cohort of patients with other common injuries (unexposed cohort). By 4 June 2008, we had enrolled all 223 patients with clinically worrisome spinal injuries from the Sichuan earthquake who met the inclusive criteria. We selected an unexposed cohort similar in size to the exposed cohort of 223 consecutive patients. To avoid the confounding effect of seasonal activity and clothing, our unexposed cohort was collected during a similar time frame of 1 May 2009 to 22 July 2009.

\section{MDCT protocols}

Among the earthquake-exposed cohort, spinal CT scans of 10,175 and 38 patients were performed using the Philips Brilliance 64-slice MDCT (Philips Healthcare, Eindhoven, the Netherlands), the Siemens Somatom Sensation 16-slice MDCT and the Siemens Somatom Plus 4-slice MDCT (Siemens Medical Systems, Forchheim, Germany), respectively. Among the unexposed common injury cohort, the 223 spinal CT scans were performed using the Siemens Somatom Sensation 16-slice MDCT. Each patient underwent MDCT along the $z$-axis from the upper two vertebrae to the lower two vertebrae of the target vertebrae. Scanning parameters were $140 \mathrm{kV}, 250 \mathrm{mAs}$, rotation time $1.0 \mathrm{~s}$, pitch 1.235 and collimation of $64 \times 0.625 \mathrm{~mm}$ for the Philips Brilliance $64 \mathrm{MDCT}$ scanner; $120 \mathrm{kV}, 250 \mathrm{mAs}$, rotation time $0.75 \mathrm{~s}$, pitch 1.0 and collimation of $16 \times 0.75 \mathrm{~mm}$ for the Siemens Somatom Sensation 16-MDCT scan; and $120 \mathrm{kV}, 180 \mathrm{mAs}$, rotation time $0.75 \mathrm{~s}$, pitch 1.5 and collimation of $4 \times 1.0 \mathrm{~mm}$ for the Siemens Somatom Plus 4 MDCT scan. The axial image data were reconstructed in 1- to 2-mm thickness and 0.7- to 1.0$\mathrm{mm}$ increments and transferred to syngo Workflow software of the picture achieving and communicating system work station (PACS; Siemens Medical Solutions).

\section{Image analysis}

All MDCT scans were read independently by two experienced radiologists (ZGY and ZHD, with 23 and 9 years of experience, respectively) on a syngo Workflow PACS workstation on which we obtained axial images and multiplanar reformatted sagittal and coronal images. Surface-shaded display was used to evaluate the vertebral fractures and the deformation of the spinal column. Discrepancies in interpretation were resolved by consensus.

At each vertebral site, the presence of fractures in the vertebral body, including the transverse processes, spinous processes, articular processes and isthmus of the vertebrae, as well as the degree of spinal canal narrowing, were evaluated, with differences resolved by consensus. We categorized the injury patterns and regions of spinal injuries and correlated these findings with the mechanism of injury and the clinician-evaluated Frankel level [6]. Spinal injuries were subdivided into major and minor injuries [9].

Major spinal injuries were categorized according to the Magerl (AO) classification because it allows categorization of injuries to all relevant parts of the spine (Figures 1, 2, 3, 4) [10-12]. As for Magerl AO types, spinal injuries are grouped as type A, type B and type $\mathrm{C}$ lesions. Type A (compression injuries of the anterior column) is subdivided into A1 (impaction fractures), A2 (split fractures) and A3 (burst fractures). Type B (distraction injuries of the anterior and posterior columns with transverse disruption) is subdivided into B1 (posterior disruptions that are predominantly ligamentous), B2 (posterior disruptions that are predominantly osseous) and B3 (anterior disruptions through the disk). Type $C$ (anterior and posterior element injuries with superimposed rotation resulting from axial torque) is subdivided into $\mathrm{C} 1$ (type $\mathrm{A}$ injuries with rotation), $\mathrm{C} 2$ (type B injuries with rotation) and C3 (rotational shear injuries). Injuries of three to seven cervical vertebrae 


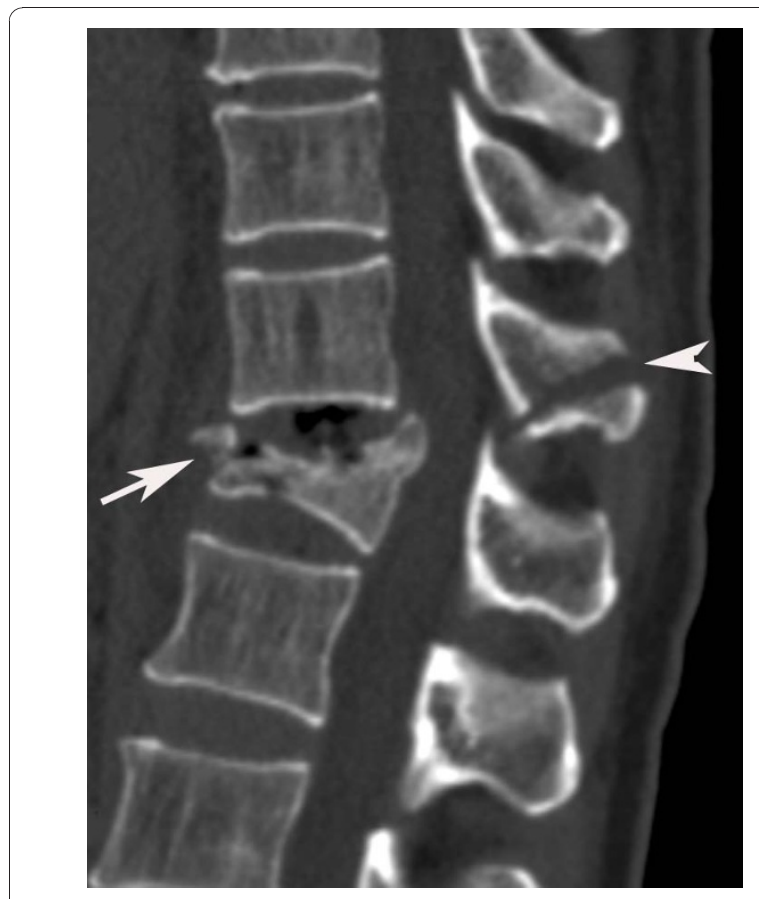

Figure 1 Reformatted sagittal image clearly shows spinous process distraction of T11 (arrowhead) and associated burst fracture (type A3) of T12 (arrow). Thus this is a Magerl (AO: Arbeitsgemeinschaft fur Osteosynthesefragen classification) type B2 lesion (posterior disruptions that predominantly involved osseous).

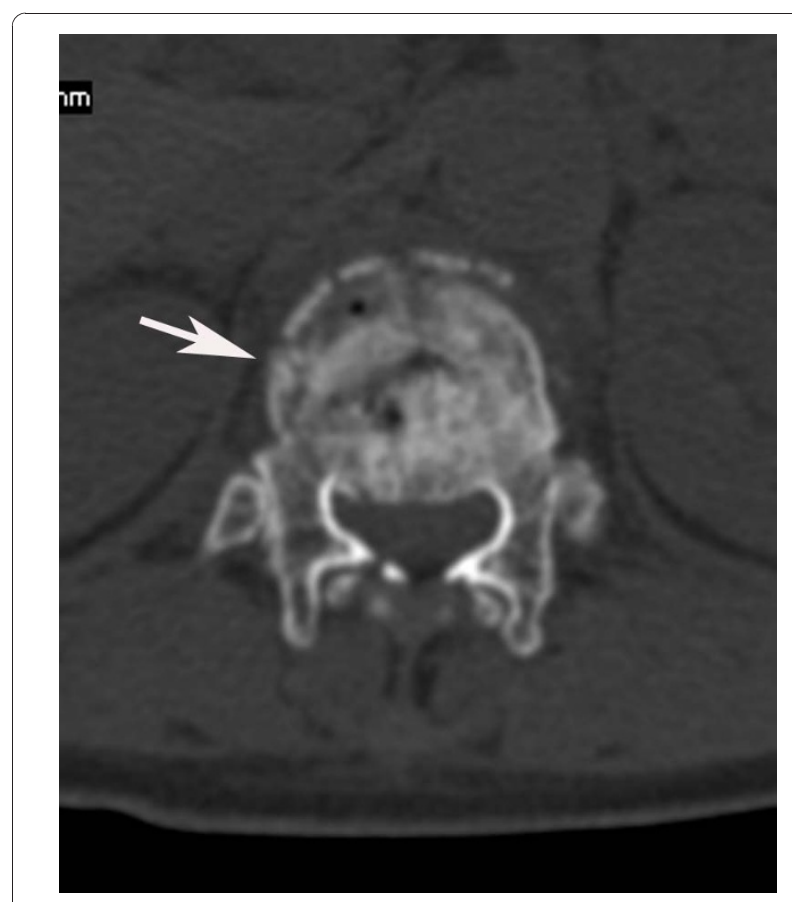

Figure 2 Cross-sectional image of the same patient as in Figure 1 clearly shows the associated burst fracture (type A3) of T12 (arrow) and the spinal canal narrowing degree of 1 (constriction of one third of the spinal canal).

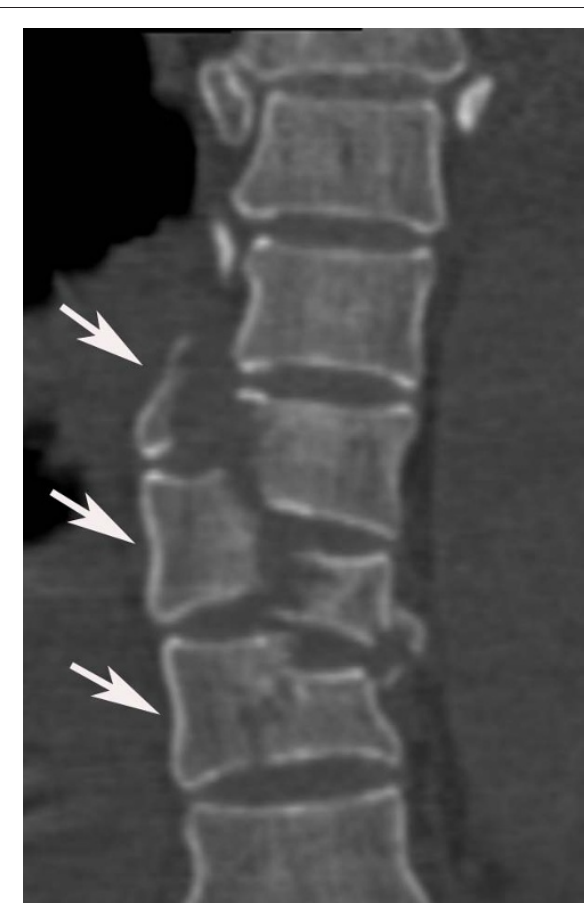

Figure 3 Reformatted coronal image of a 51-year-old female patient who had crush trauma as a result of an earthquake shows an oblique fracture from T5 through T7 and form type C3 lesions.

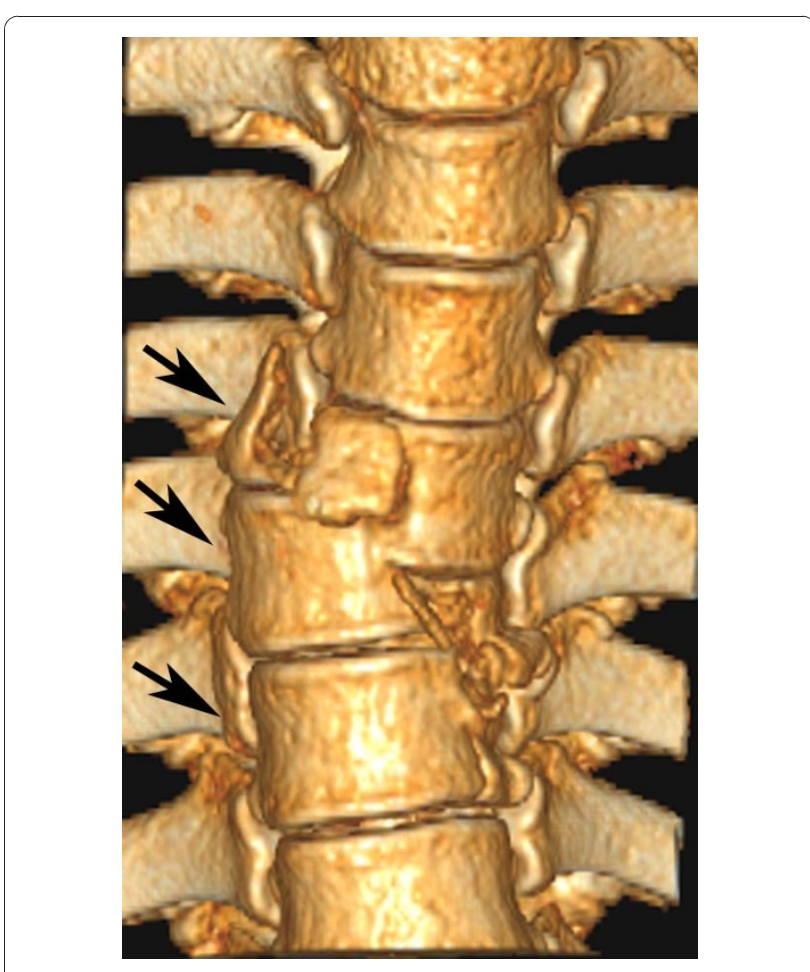

Figure 4 Surface-shaded display of a 51-year-old female patient shows type C3 lesions from T5 through T7. 
were categorized according to the Magerl AO classification because they were similar to injuries of the thoracic and lumbar spine. We classified teardrop fractures, occipital condyle fractures, Jefferson fractures, odontoid fractures, hangman's fractures, lateral mass fractures and posterior arch or laminar fractures as major injuries. Minor injuries, on the other hand, included isolated or combined fractures of transverse processes, facets, pars interarticularis, spinous process and atlantoaxial subluxation.

Spinal canal narrowing was measured in all injured vertebrae at the point of greatest narrowing and was defined as 0 (no constriction of the spinal canal), 1 (constriction of one third of the spinal canal), 2 (constriction of two thirds of the spinal canal) and 3 (constriction of all of the spinal canal), respectively [13]. The neurologic function impairment grades were classified according to the widely accepted Frankel grading method because of its ease of use and lack of subjectivity [6]. Patients were graded as Frankel level of (A) complete, (B) sensory only, (C) motor useless, (D) motor useful and (E) recovery.

\section{Statistical analysis}

Data for each patient were entered into a Microsoft Excel database (Microsoft Corporation, Redmond, WA, USA). We performed data analysis on a personal computer using the SPSS statistical package (version 13.0 for Windows; SPSS Inc., Chicago, IL, USA). We determined the differences between the earthquake-exposed and non-earthquake-exposed cohorts using risk ratios (RRs) and the Mann-Whitney $U$ test for gender, age (categorized as ages $<35$ years, 35-64 years and $>64$ years) and anatomic distribution of injury (categorized as cervical, thoracic and lumbar spine). Additionally, the anatomic distributions and types of injuries were compared using the $\chi^{2}$ test, and the patient's age and spinal canal narrowing degrees were compared using the Mann-Whitney $U$ test. The Kruskal-Wallis $\mathrm{H}$ test was performed to compare the spinal canal narrowing degrees between different AO types of injuries. We accepted two-tailed $P$ values less than 0.05 as a statistically significant difference.

\section{Results}

The earthquake-exposed cohort included 119 (53.36\%) female patients and 104 (46.64\%) male patients, with ages ranging from 3 to 89 years (mean age, 45 years) including 56,118 and 49 patients grouped by ages $<35$, 35-64 and $>64$ years, respectively. The mean hospital stay was 13.6 days, ranging from 1-203 days. Only one 74-year-old female patient died as a result of heart failure from septic shock related to thoracoabdominal blunt trauma. The non-earthquake-related cohort included
53 (23.77\%) female patients and $170(76.23 \%)$ male patients whose ages ranged from 1.8 to 88 years (mean age, 40 years) including 80,124 and 19 patients in the age groups $<35,35-64$ and $>64$ years, respectively. The mean hospital stay was 11 days and ranged from 1-113 days. Three patients died, including one patient whose spinal injury was combined with a head injury, one patient with an injury of cervical spine due to a gunshot wound and one patient with multiorgan injury. Male patients were statistically more common in the nonearthquake-related spinal injury cohort $(R R=1.63$, Mann-Whitney $U$ test $=6.418$ and $P<0.001$ ). We also found that young patients more commonly represented in the non-earthquake-related injury cohort $(Z$-score $=$ -3.753, $P<0.001$ ).

\section{Cause and anatomical distribution of spinal injuries}

Of the earthquake-exposed cohort, 185 patients (82.96\%) sustained crush injuries and 38 had fallen with resultant injury. For the non-earthquake-related spinal injury cohort, on the other hand, the proximate causes of injury included falls (90 patients), motor vehicle accidents (71 patients), crush injuries (26 patients), assault and gunshot wounds. The numbers and anatomic distribution of spinal injuries detected in the earthquakeexposed and non-earthquake-exposed cohorts are listed in Table 1. We found a significant difference in the anatomic distribution of these two cohorts $\left(\chi^{2}=19.457\right.$, $P<0.001)$. The cervical spinal injuries presented more frequently in patients with non-earthquake-related spinal injuries than in patients with earthquake-related injuries $(\mathrm{RR}=2.12$, Mann-Whitney $U$ test $=5.739$ and $P<0.001$ ), including both the cervical major spinal injuries $(\mathrm{RR}=1.95$, Mann-Whitney $U$ test $=4.148$ and $P<0.001$ ) (Figure 5) and the cervical minor spinal

\section{Table 1 Number and anatomic distributions of spinal injuries detected in earthquake-related and non- earthquake-related injuries}

\begin{tabular}{lcc}
\hline Injury & $\begin{array}{c}\text { Earthquake-related } \\
\text { injuries (exposed } \\
\text { cohort) }\end{array}$ & $\begin{array}{c}\text { Non-earthquake-related } \\
\text { injuries (unexposed } \\
\text { cohort) }\end{array}$ \\
\hline $\begin{array}{l}\text { Type of injury } \\
\text { Spinal injuries }\end{array}$ & $198 / 501$ & $167 / 438$ \\
$\begin{array}{l}\text { Major injuries } \\
\text { Minor injuries }\end{array}$ & $173 / 252$ & $155 / 255$ \\
Anatomic \\
distributions \\
(vertebrae) \\
Cervical \\
spine \\
$\begin{array}{l}\text { Thoracic } \\
\text { spine }\end{array}$ \\
$\begin{array}{l}\text { Lumbar } \\
\text { spine }\end{array}$
\end{tabular}




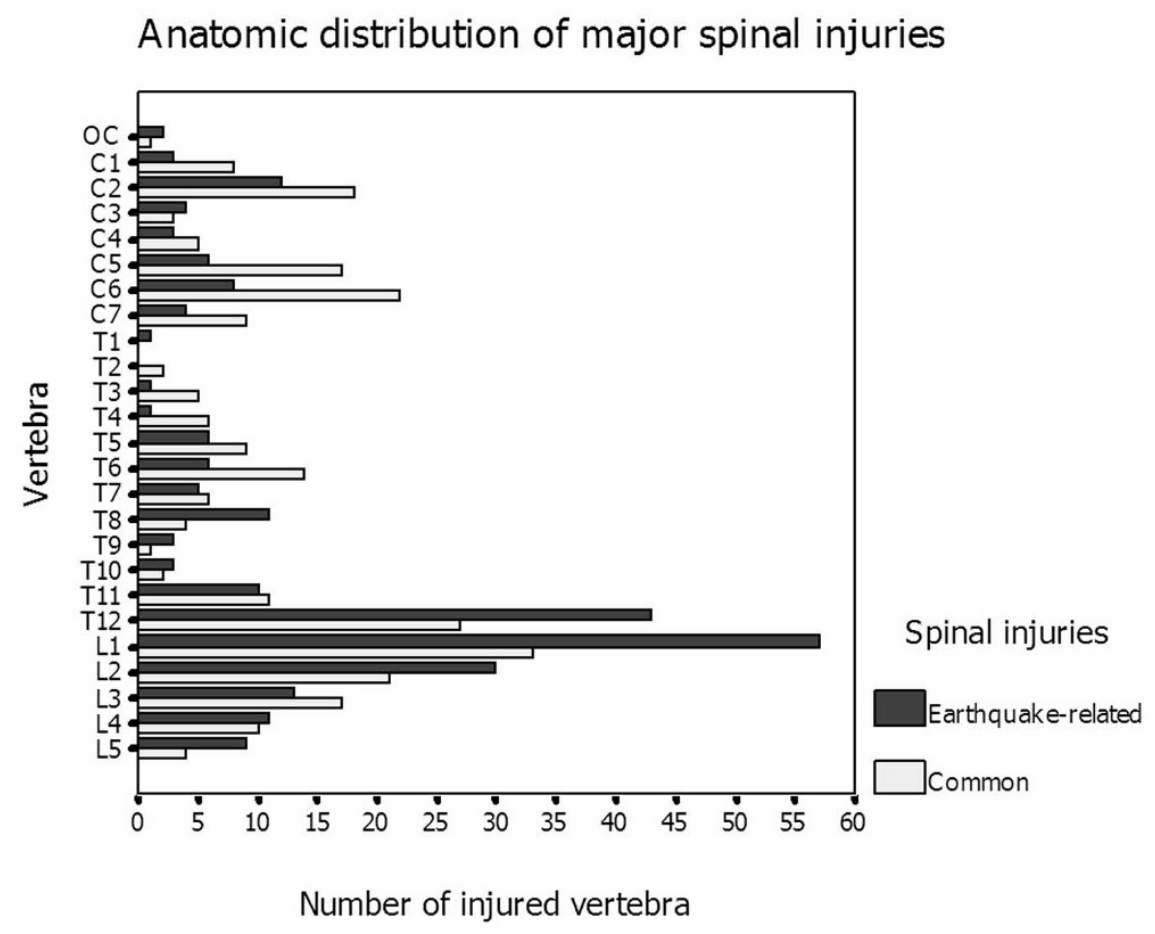

Figure 5 Clustered bar chart shows that earthquake-related major spinal injuries were most commonly seen in the lumbar spine with the peak prevalence being in the T12-L2 vertebra. Non-earthquake-related major spinal injuries were distributed equally in the cervical, thoracic, and lumbar spine.

injuries $(\mathrm{RR}=2.25$, Mann-Whitney $U$ test $=3.661$ and $P<0.001$ ) (Figure 6). Multilevel major injuries were detected in 59 patients $(34.10 \%$ of 173 patients) in the earthquake-exposed cohort (two to five vertebrae; average, two vertebrae), of which 22 patients (37.29\%) did not have an adjacent spinal level injury. Similarly, 61 patients (39.35\% of 155 patients) had multilevel involvement in the non-earthquake-related spinal injury cohort (two to six vertebrae; average, two vertebrae), with 26 patients $(42.62 \%)$ not presenting with adjacent vertebral involvement.

\section{Types of spinal injuries}

Of the 252 earthquake-related major spinal injuries, types A, B and C lesions were detected in 155, 45 and 22 vertebrae, respectively, which was significantly different from the findings in the non-earthquake-related cohort, in whom types A, B and C lesions were detected in 127,36 and 44 vertebrae, respectively (Figure 7) $\left(\chi^{2}=15.250, P=0.002\right)$. Type $C$ lesions were seen more commonly in the non-earthquake-related spinal injury patients than in the earthquake-related spinal injury patients $(\mathrm{RR}=1.98$, Mann-Whitney $U$ test $=2.760$ and $P=0.0029)$. However, the incidence of type B lesions was relatively higher in patients with earthquake-related injuries (20.27\% of AO type fractures) than in those with non-earthquake-related spinal injuries $(R R=1.27)$. Associated type A3 fractures were detected in 31 earthquake-related type B lesions (72.09\% of the 43 type B lesions that associate with type A fractures). Other categories of major injuries are listed in Table 2. Of the minor injuries, transverse process fractures were the main type of injury in both cohorts (Table 3 ).

\section{Spinal canal narrowing and neurologic deficit}

The degree of spinal canal narrowing in both cohorts is listed in Table 4. No statistically significant difference was found in these two cohorts $(Z$-score $=-0.727, P=$ 0.467). The degree of spinal canal narrowing increased significantly from Magerl type A through type $C$ injuries $\left(\chi^{2}=14.4, P=0.001\right.$, for earthquake-exposed patients; $\chi^{2}=47.023, P<0.001$, for the non-earthquake-exposed cohort) (Table 4).

Neurologic deficits such as decreased perineal sensation, limb anesthesia, bladder dysfunction, muscle weakness and paraplegia occurred in 65 patients $(29.15 \%$; 95\% CI, 23.19-35.11\%) in the earthquake-related cohort, with a Frankel level of A, B, C and D in 14, 8, 24 and 19 patients, respectively. For the non-earthquake-related cohort, neurologic deficits occurred in 92 patients 


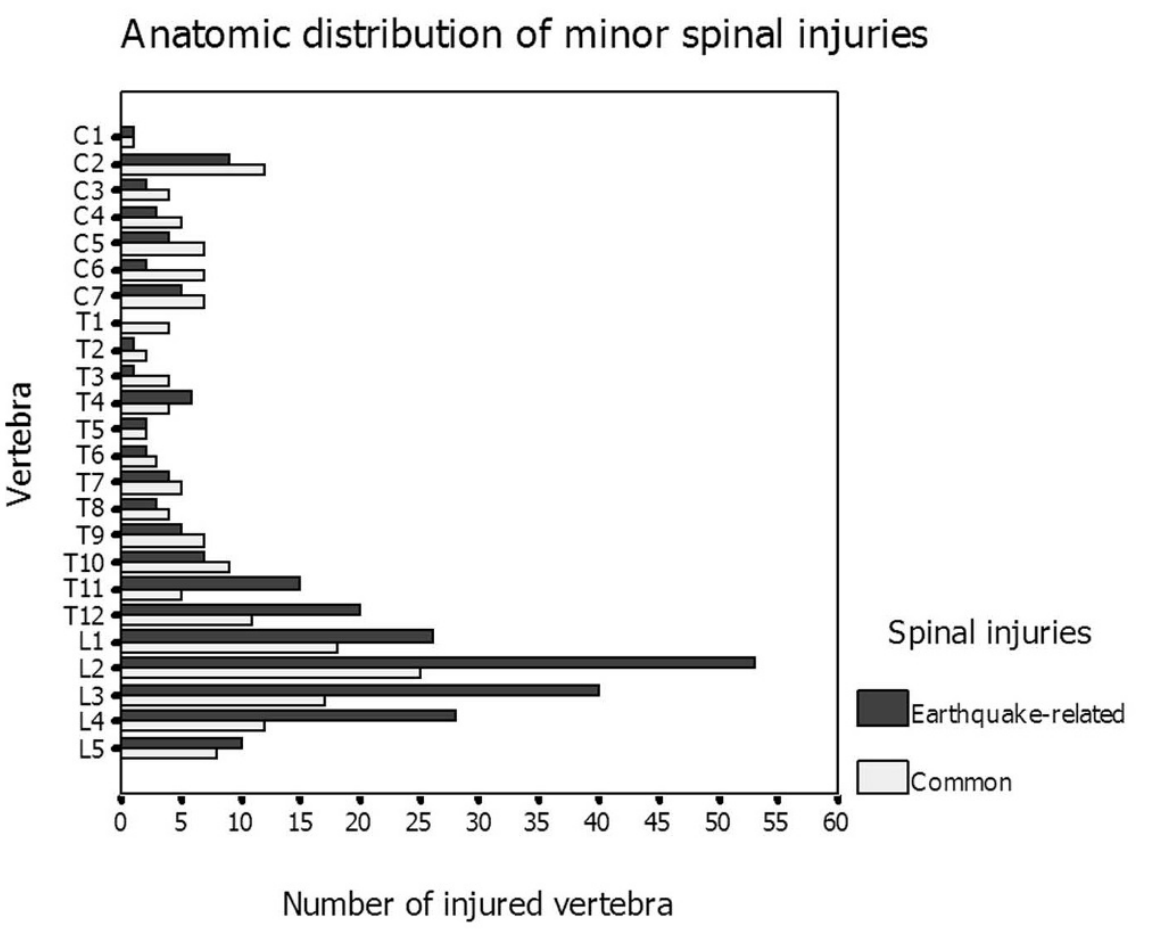

Figure 6 Clustered bar chart shows that minor earthquake-related spinal injuries were more frequently involved in the lumbar spine than non-earthquake-related injuries, with the peak incidence in the T12-L4 vertebra.

(41.26\%; 95\% CI, 34.80-47.72\%), with a Frankel level of A, B, C and D in 41, 12, 24 and 15 patients, respectively. Spinal canal narrowing was much higher in patients with neurologic deficits than in patients without neurologic deficits (Table 5$)$ ( $Z$-score $=-3.498$ for earthquake-exposed cohort and $Z$-score $=-10.382$ non-earthquake-exposed cohort, respectively; $P<0.001)$. Furthermore, the incidence of neurological deficit

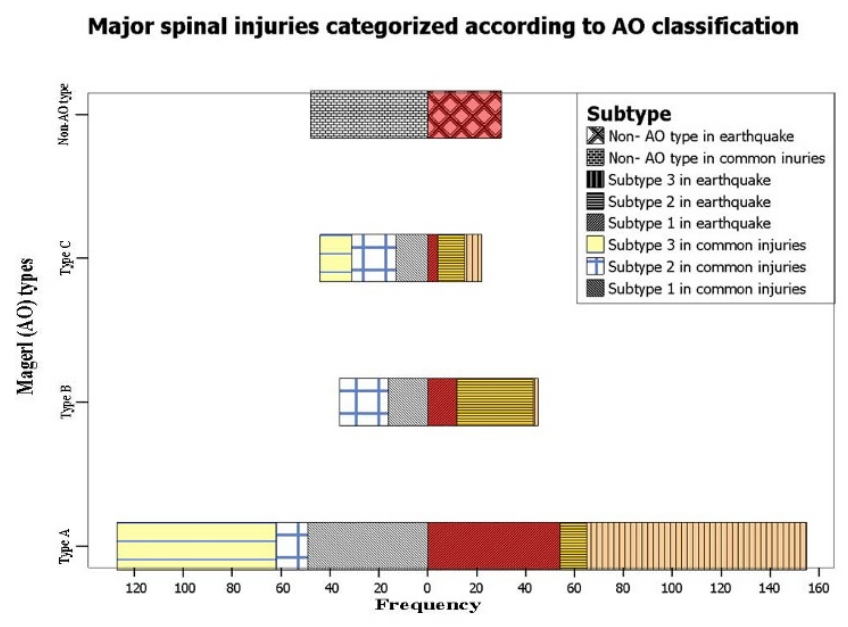

Figure 7 Stacked bar chart shows that type A spinal injuries were the main type of AO spinal injuries detected in both earthquakerelated and non-earthquake-related spinal injuries. In earthquake-related spinal injuries, type A3 injuries compose 58.06\% of type A injuries. 
Table 2 Non-AO-type classification of major spinal injuries $^{a}$

\begin{tabular}{lcc}
\hline $\begin{array}{l}\text { Types of } \\
\text { fractures }\end{array}$ & $\begin{array}{c}\text { Earthquake-related } \\
\text { vertebral injuries (\%) }\end{array}$ & $\begin{array}{c}\text { Non-earthquake-related } \\
\text { vertebral injuries (\%) }\end{array}$ \\
\hline Teardrop & $4(13.33)$ & $13(27.08)$ \\
Occipital condyle & $2(6.67)$ & $1(2.08)$ \\
Jefferson fractures & $1(3.33)$ & $5(10.42)$ \\
Odontoid & $10(20.83)$ \\
processes & $5(16.67)$ & $8(16.67)$ \\
$\begin{array}{l}\text { Hangman's } \\
\text { fractures }\end{array}$ & $4(13.33)$ & $3(6.25)$ \\
Lateral mass or & $4(13.33)$ & $8(16.67)$ \\
anterior arch & $10(33.33)$ & $48(100)$ \\
$\begin{array}{l}\text { Posterior arch or } \\
\text { laminar fractures }\end{array}$ & $30(100)$ & \\
Total &
\end{tabular}

${ }^{a}$ Non-AO-type classification represents classifications of major spinal injuries that cannot be classified by the grid 3-3-3 scheme of the AO fracture classification established by Magerl $[6,10]$

increased significantly from Magerl type A through type C: neurological deficit was associated with $21.99 \%$ of type A lesions, $40.74 \%$ of type B lesions and $69.70 \%$ of type $\mathrm{C}$ lesions $\left(\chi^{2}=57.156, P<0.001\right)$.

\section{Discussion}

Spinal injuries are common in both trauma associated with earthquakes and other major blunt traumas [2-5]. A spinal cord injury can be disabling or life threatening with poor long-term physical and psychological consequences [14-16]. Non-earthquake-related spinal injuries rarely occur as a result of crush injury $[8,17]$. In our earthquake-exposed cohort, however, crush injury was the leading cause of spinal injury. As spinal injuries occur most commonly in males during the summer months and on weekends [6], we chose a non-earthquake-related cohort from a similar time of the year in 2009 to avoid the bias introduced by the confounding effect of seasonal activity and clothing.

Table 3 Minor injuries detected in earthquake-related and non-earthquake-related injuries

\begin{tabular}{lcc}
\hline Injuries & $\begin{array}{c}\text { Earthquake-related } \\
\text { vertebral injuries (\%) }\end{array}$ & $\begin{array}{c}\text { Non-earthquake-related } \\
\text { vertebral injuries (\%) }\end{array}$ \\
\hline $\begin{array}{l}\text { Transverse } \\
\text { process } \\
\text { fractures }\end{array}$ & $155(62.25)$ & $112(61.20)$ \\
$\begin{array}{l}\text { Spinous } \\
\text { process } \\
\text { fractures }\end{array}$ & $36(14.46)$ & $29(15.85)$ \\
$\begin{array}{l}\text { Facet fractures } \\
\text { Combined } \\
\text { fractures }\end{array}$ & $16(6.42)$ & $4(2.19)$ \\
$\begin{array}{l}\text { Atlantoaxial } \\
\text { subluxation }\end{array}$ & $33(13.25)$ & $10(15.30)$ \\
Total & $9(3.61)$ & $183(100)$ \\
\hline
\end{tabular}

We found young male patients were more commonly involved in non-earthquake-related spinal injuries, which concurs with previous data. This difference between the cohort populations can probably be attributed to the fact that falls and motor vehicle injuries are the two primary causes of non-earthquake-related spinal injuries. Most work-related falls from elevated height occur in young males, and drivers injured in motor vehicle collisions also tend to be young males, consistent with previous Chinese data. In the earthquake, however, agile young males would be more likely to escape danger and withstand vertebral trauma. On the other hand, as the earthquake occurred during working hours in the mountainous area of China, most of the males were working and alert. In contrast, unemployed and older adult females were at home and relatively relaxed. Thus, the sudden, intense earthquake would be more likely to injure the latter group. Our results indicate that it was necessary to increase attention to female and older adult patients in the ward preparation and staff scheduling.

As described by Velez and Newell [6], the majority of spinal injuries in general blunt trauma occur at the level of the cervical spine, followed by thoracic, thoracolumbar and lumbosacral spinal injuries. In our study, the anatomic distributions of these two cohorts were significantly different. In our earthquake-related cohort, we found lumbar spinal injuries were most common, with the peak incidence being in the T12 to L3 region, similar to the results of a study of spinal cord injuries sustained in a Pakistani earthquake [18]. This finding possibly results from random distribution of the crushrelated forces exerted on the spinal column. The larger vertebrae occupy a longer section of the spinal column, which relates to a higher chance of exposure to spinal crush injuries. In the non-earthquake-related cohort, however, both major and minor cervical spine injuries occurred with increased frequency; thus major injuries were distributed fairly equally among the cervical, thoracic and lumbar spine. Possible explanations for this finding include the cervical spine's mobility and flexibility, lack of protection by a rib cage and fragility compared to the lumbar spine. Furthermore, all traumas to the cervical spine result in a high incidence of some kind of neurologic injury-related mortality [6], which made the patients less likely to survive the disaster. We noticed that multiple fractures were common in both cohorts of this series and that more than one third of spinal injuries were not adjacent to each other, which stresses the importance of evaluating the entire spine after injury in either earthquake-related or non-earthquake-related injuries.

The mechanisms of spinal fractures include simple flexion, flexion-distraction, flexion and compression, 
Table 4 Degrees of major injuries involving spinal canal narrowing ${ }^{a}$

\begin{tabular}{|c|c|c|c|c|c|}
\hline \multirow[b]{2}{*}{ Cohort } & \multicolumn{4}{|c|}{ Spinal canal narrowing degrees (vertebrae) } & \multirow[b]{2}{*}{ Total } \\
\hline & 0 & 1 & 2 & 3 & \\
\hline Earthquake-related injuries & 110 & 76 & 50 & 16 & 252 \\
\hline Non-earthquake-related injuries & 129 & 56 & 44 & 26 & 255 \\
\hline AO type & \multicolumn{5}{|c|}{ Earthquake-related/non-earthquake-related (vertebrae) } \\
\hline Type A & $68 / 72$ & $47 / 29$ & $34 / 22$ & $6 / 4$ & $155 / 127$ \\
\hline Type B & $11 / 16$ & $20 / 7$ & $10 / 8$ & $4 / 5$ & $45 / 36$ \\
\hline Type C & $3 / 2$ & $7 / 13$ & $6 / 14$ & $6 / 15$ & $22 / 44$ \\
\hline
\end{tabular}

${ }^{\mathrm{a}} \chi^{2}=14.4, P=0.001$, for earthquake-related injuries. $\chi^{2}=47.023, P<0.001$, for non-earthquake-related injuries.

extension, "shearing" forces and rotation [19]. Of these, compression, distraction and rotation (axial torque) are the most important mechanisms. Using mechanism of injury, pathomorphological uniformity and healing potential, Magerl established the grid 3-3-3 scheme of the AO fracture classification [10]. In a series of traumatic spinal injuries investigated by Magerl et al. [10], type A fracture occurred most commonly (66.1\%), whereas types $C$ and B occurred in $19.4 \%$ and $14.5 \%$ of patients, respectively. In our investigation, type A injuries composed $69.82 \%$ of $\mathrm{AO}$ type fractures in patients with earthquake-related injuries, with a RR of 1.23 compared to patients with non-earthquake-related injuries. The higher incidence of type A fractures was possibly a result of the direct vertical force or axial loading caused by falling objects that caused compression fracture. Types $B$ and $C$ injuries tend to be caused by flexion violence, which is more common in motor vehicle collisions and falls $[19,20]$. The comparatively high incidence of type $\mathrm{C}$ lesions found in the non-earthquake-related cohort of this study is consistent with these mechanisms of fall and motor vehicle trauma.

According to the AO classification system applied in the present study, earthquake-related type B lesions occurred more often than other types, with a RR of 1.27 as compared to common spinal injuries. We hypothesized that the forces of falling objects on the victims who were most likely in anterior flexion, combined with the axial loading or vertical force, might invoke a flexion and distraction component. The axis of rotation adjacent to the posterior vertebral body cortex may result in associated anterior compression. When the axis of rotation is beyond the posterior longitudinal ligament, combined type A3 compression fractures tended to occur. In this manner, all three sections of the spinal column can fail because of flexion and distraction with initial axial loading, resulting in an unstable type $B$ lesion. The high incidence of associated type A3 fractures suggests that spinal crush injuries are different from seat belt or chance fractures, in which the initial force is flexion and distraction and the fulcrum is mainly the anterior column [7]. These results indicate that we should pay more attention to the detection and management of type B fractures in earthquake victims.

Clinically, neurologic sequelae serve as one of the most important factors in assessing spinal injuries and clinical management $[4,6,9,15,16]$. Of all the spinal injuries, spinal cord injuries may occur in $4.9-9.0 \%$ of patients in the early postfracture period [5-21]. In our series, the incidence of neurologic deficit was much higher in both cohorts. The incidence of neurological deficits increased significantly between AO types, which is similar to the finding of Magerl et al. [10]. Our study also revealed that the degree of spinal canal narrowing was higher in patients with neurologic deficits.

Minor injuries compose about $16.95 \%$ of all spinal fractures [19]. The clinical importance of these injuries is still controversial $[22,23]$. As shown in our study, almost half of injuries from the earthquake-related spinal injury group were minor injuries. This might be a result of the high sensitivity of MDCT in detecting these injuries. Otherwise, a wide anatomic distribution of minor fractures might reveal that the injuries in the earthquake-related injury cohort were widespread multiregional injuries, which once again stresses the need to scan the entire spinal column.

Table 5 Degrees of spinal canal narrowing in patients with or without neurologic deficit ${ }^{\mathrm{a}}$

\begin{tabular}{|c|c|c|c|c|c|}
\hline \multirow[b]{2}{*}{ Neurologic deficit } & \multicolumn{4}{|c|}{ Narrowing degrees (patients) } & \multirow[b]{2}{*}{ Total } \\
\hline & 0 & 1 & 2 & 3 & \\
\hline \multicolumn{6}{|l|}{ Earthquake-related injuries } \\
\hline Number of patients (with/without) & $18 / 63$ & $15 / 61$ & $21 / 29$ & $11 / 5$ & $65 / 158$ \\
\hline \multicolumn{6}{|l|}{ Non-earthquake-related injuries } \\
\hline Number of patients (with/without) & $12 / 104$ & $24 / 20$ & $33 / 6$ & $23 / 1$ & $92 / 131$ \\
\hline
\end{tabular}

${ }^{a} Z$-score $=-3.498, P<0.001$ for earthquake-related cohort. $Z$-score $=-10.382, P<0.001$ for non-earthquake-related spinal injuries. 
Our study has limitations. Since our hospital is a major medical center in the southwest region of China, some severely injured patients were transferred from the local hospital and may have had progression to neurologic sequelae in the process of being transported to our site. Although we selected the data consecutively to try our best to avoid selection bias, the comparatively high incidence of neurologic deficits in the non-earthquakerelated cohort perhaps is due to this type of bias.

\section{Conclusions}

Spinal injuries sustained in the Sichuan earthquake were mainly caused by crush injuries and included a high incidence of neurologic deficits. The thoracolumbar region is the most common site of spinal fracture, and type A fractures are the most common type of major injury. The major injuries of patients with non-earthquake-related spinal injuries were equally distributed among the cervical, thoracic and lumbar spine, with a comparatively high incidence of type $\mathrm{C}$ lesions, which were significantly different from the distribution observed among patients with earthquake-related injuries, which perhaps were due to the special mechanism associated with the earthquake.

\section{Key messages}

- The leading cause of spinal injuries in the Sichuan earthquake was crush injuries.

- Earthquake-related spinal injuries were mainly involved in the thoracolumbar region and resulted in type A fractures with a high incidence of neurologic deficits.

- The causes of non-earthquake-related spinal injuries were significantly different from earthquakerelated injuries, including falls, motor vehicle accidents, crush injuries, assaults and gunshot wounds.

- Non-earthquake-related spinal injuries were equally distributed among the cervical, thoracic and lumbar spine, with a comparatively high incidence of type $\mathrm{C}$ lesions.

\section{Abbreviations}

AO: Arbeitsgemeinschaft fur Osteosynthesefragen; $\mathrm{Cl}$ : confidence interval; $\mathrm{CT}$ : computed tomography; MDCT: multidetector computed tomography; PACS: picture achieving and communicating system; RR: risk ratio.

\section{Acknowledgements \\ This article is supported by National Nature Sciences Foundation of China grants 30970820 and 30870688. This study was supported by Science Foundation for Distinguished Young Scholars of Sichuan Province grant 2010JQ0039.}

\section{Author details}

'Department of Radiology, West China Hospital of Sichuan University, Chengdu 610041, China. ${ }^{2}$ State Key Laboratory of Biotherapy, West China Hospital of Sichuan University, Chengdu 610041, China. ${ }^{3}$ Department of
Senior Services, Methodist Hospital, Park Nicollet Clinic, St. Louis Park, MN 55416, USA.

\section{Authors' contributions}

ZGY and ZHD conceived and organized the study. ZHD, TWC, ZGC, QLW and WD participated in the acquisition of data. ZGY, ZHD, TWC, ZGC and $J C D$ performed the statistical analysis and interpretation of data. ZGY, ZHD, TWC, ZGC and JCD participated in the drafting of the manuscript. All authors read and approved the final version of the manuscript.

\section{Competing interests}

The authors declare that they have no competing interests.

Received: 24 July 2010 Revised: 7 November 2010

Accepted: 29 December 2010 Published: 29 December 2010

\section{References}

1. Dong ZH, Yang ZG, Chen TW, Feng YC, Wang QL, Chu ZG: Spinal injuries in the Sichuan earthquake. N Engl J Med 2009, 361:636-637.

2. Peek-Asa C, Kraus JF, Bourque LB, Vimalachandra D, Yu J, Abrams J: Fatal and hospitalized injuries resulting from the 1994 Northridge earthquake. Int J Epidemiol 1998, 27:459-465.

3. Nakamori Y, Tanaka H, Oda J, Kuwagata Y, Matsuoka T, Yoshioka T: Burn injuries in the 1995 Hanshin-Awaji earthquake. Burns 1997, 23:319-322.

4. Schinkel C, Frangen TM, Kmetic A, Andress HJ, Muhr G, AG Polytrauma der DGU: [Spinal fractures in multiply injured patients: an analysis of the German Trauma Society's Trauma Register] (in German). Unfallchirurg 2007, 110:946-952.

5. Roche SJ, Sloane PA, McCabe JP: Epidemiology of spine trauma in an Irish regional trauma unit: a 4-year study. Injury 2008, 39:436-442.

6. Velez DA, Newell DW: Spine injuries. In Neurosurgery: Principles and Practice. Edited by: Moore AJ, Newell DW. London: Springer; 2005:379-405.

7. Bernstein MP, Mirvis SE, Shanmuganathan K: Chance-type fractures of the thoracolumbar spine: imaging analysis in 53 patients. AJR Am J Roentgenol 2006, 187:859-868.

8. Wintermark M, Mouhsine E, Theumann N, Mordasini P, van Melle G, Leyvraz PF, Schnyder P: Thoracolumbar spine fractures in patients who have sustained severe trauma: depiction with multi-detector row CT. Radiology 2003, 227:681-689.

9. Denis F: The three column spine and its significance in the classification of acute thoracolumbar spinal injuries. Spine 1983, 8:817-831.

10. Magerl F, Aebi M, Gertzbein SD, Harms J, Nazarian S: A comprehensive classification of thoracic and lumbar injuries. Eur Spine J 1994, 3:184-201.

11. Wood KB, Khanna G, Vaccaro AR, Arnold PM, Harris MB, Mehbod AA: Assessment of two thoracolumbar fracture classification systems as used by multiple surgeons. J Bone Joint Surg Am 2005, 87:1423-1429.

12. Oner FC, Ramos LM, Simmermacher RK, Kingma PT, Diekerhof $C H$, Dhert WJ, Verbout AJ: Classification of thoracic and lumbar spine fractures: problems of reproducibility. A study of 53 patients using CT and MRI. Eur Spine J 2002, 11:235-245.

13. Wolter D: [Classification and prognosis of spinal injuries] [in German]. Langenbecks Arch Chir 1988, Suppl 2: 237-243.

14. Capoor J, Stein AB: Aging with spinal cord injury. Phys Med Rehabil Clin N Am 2005, 16:129-161.

15. Rathore FA, Faroog F, Muzammil S, New PW, Ahmad N, Haig AJ: Spinal cord injury management and rehabilitation: highlights and shortcomings from the 2005 earthquake in Pakistan. Arch Phys Med Rehabil 2008, 89:579-585.

16. Raissi GR, Mokhtari A, Mansouri K: Reports from spinal cord injury patients: eight months after the 2003 earthquake in Bam, Iran. Am J Phys Med Rehabil 2007, 86:912-917.

17. Durham RM, Luchtefeld WB, Wibbenmeyer L, Maxwell P, Shapiro MJ, Mazuski JE: Evaluation of the thoracic and lumbar spine after blunt trauma. Am J Surg 1995, 170:681-685.

18. Tauqir SF, Mirza S, Gul S, Ghaffar H, Zafar A: Complications in patients with spinal cord injuries sustained in an earthquake in Northern Pakistan. $J$ Spinal Cord Med 2007, 30:373-377.

19. Perugini $S$, Ghirlanda S, Rossi R, Bonetti MG, Salvolini U: CT in spinal trauma emergencies. In Emergency Neuroradiology. Edited by: Scarabino T, Salvolini U, Jinkins R. Berlin: Springer; 2006:299-320. 
20. Holdsworth F: Fractures, dislocations, and fracture-dislocations of the spine. J Bone Joint Surg Am 1970, 52:1534-1551.

21. Velmahos GC, Spaniolas K, Alam HB, de Moya M, Gervasini A, Petrovick L, Conn AK: Falls from height: spine, spine, spine! J Am Coll Surg 2006, 203:605-611.

22. Patten RM, Gunberg SR, Brandenburger DK: Frequency and importance of transverse process fractures in the lumbar vertebrae at helical abdominal CT in patients with trauma. Radiology 2000, 215:831-834.

23. Goldberg W, Mueller C, Panacek E, Tigges S, Hoffman JR, Mower WR, NEXUS Group: Distribution and patterns of blunt traumatic cervical spine injury. Ann Emerg Med 2001, 38:17-21.

doi:10.1186/cc9391

Cite this article as: Dong et al.: Earthquake-related versus non-

earthquake-related injuries in spinal injury patients: differentiation with multidetector computed tomography. Critical Care 2010 14:R236.

\section{Submit your next manuscript to BioMed Central} and take full advantage of:

- Convenient online submission

- Thorough peer review

- No space constraints or color figure charges

- Immediate publication on acceptance

- Inclusion in PubMed, CAS, Scopus and Google Scholar

- Research which is freely available for redistribution

Submit your manuscript at www.biomedcentral.com/submit
C Biomed Central 